\title{
Bioavailability of microcystin-LR in two different soil types to the legume Alfalfa Medicago sativa L.
}

\author{
M. Esterhuizen ${ }^{1,2,3}$ (D) N. Schmitner ${ }^{4}$ (D) $\cdot$ S. Pflugmacher ${ }^{1,2,3}$ (D)
}

Received: 1 April 2020 / Revised: 28 October 2020 / Accepted: 6 January 2021 / Published online: 19 January 2021

(c) The Author(s) 2021

\begin{abstract}
The adverse effects of exposure to microcystins in terrestrial crops have been well documented. However, the retention and bioavailability of microcystin-LR, one of the most prevalent cyanotoxins, from soil to plants, is poorly understood. In the present study, the amount of free microcystin-LR from two soil types, a silty sand and clayey loam, with exposure to three toxin concentrations and time was investigated. Using the two soil types, the effects on Medicago sativa (Alfalfa) growth after microcystin-LR exposure via irrigation with spiked water and pre-spiked soil was investigated and the amount of microcystin-LR taken up by the plant quantified. After 3 weeks of growth, the amount of free microcystin-LR remaining in the two soil types with each treatment was quantified. The results indicated that in clayey loam more microcystin-LR is bound to the soil. However, the growth of Alfalfa was only affected in the clayey loam with microcystin/LR exposure via irrigation. Nevertheless, microcystin-LR was detected in Alfalfa grown in both soil types exposed by both irrigation and via pre-spiked soil. Interestingly, more microcystin-LR remained in the silty sand after 3 weeks; yet, more microcystin-LR was taken up by the Alfalfa grown in the silty sand, with a larger concentration in the roots compared to the shoots. The results indicate that the soil type substantially influences the bioavailability and uptake of microcystin-LR and present some insight into the ecological risk posed by microcystin-LR.
\end{abstract}

Keywords Absorption · Clayey loam $\cdot$ Crop plants $\cdot$ Cyanobacterial toxins $\cdot$ Hepatotoxin $\cdot$ Silty sand $\cdot$ Uptake

\section{Introduction}

The mass proliferation of cyanobacteria capable of producing various types of toxins is more common in eutrophic surface waters (Scholz et al. 2017). The most commonly occurring cyanotoxins are the microcystins (MCs), which are produced by members of several cyanobacterial genera (Huisman et al. 2018). Currently, more than 200 structural variants have been identified (Spoof and Catherine 2017). Microcystin-LR (MC-LR) is among the most frequently detected in nature and is the most toxic microcystin congener (Omidi et al. 2018). In the aquatic ecosystem, cyanotoxins such as the microcystins are typically contained intracellularly (Orr and Jones 1998); with the exception of cylindrospermopsin, which is actively released by cells (Preußel et al. 2014). However, intracellular toxins are released during cell lysis when the bloom collapses or with chemical treatments used for the eradication of cyanobacteria (Huisman et al. 2018). Thus, these water-soluble toxins, as in the case of the microcystins, would then be free within the water column, expanding the
Institute of Molecular Biology, CMBI,
Leopold-Franzens-University Innsbruck, 6020 Innsbruck, Austria 
exposure possibilities, which could result in a variety of ecological effects and even pose a threat to human health (Huisman et al. 2018). Except for direct exposure through drinking contaminated water and recreational activities, cyanotoxin exposure can also occur via consumption of, e.g. contaminated seafood (Preece et al. 2017; Lee et al. 2017) or plants (Codd et al. 1999; Contardo-Jara et al. 2014; 2018; Peuthert et al. 2007, 2015; Lee et al. 2017).

Exposure of terrestrial crops and subsequent uptake of cyanotoxins can occur through spray irrigation with untreated surface waters (Esterhuizen-Londt and Pflugmacher 2019), a practice common in many countries all over the world, or from using cyanobacterial biomass as biofertilizer (Bouaicha and Corbel 2016). The uptake of these toxins by agricultural plants poses a potential risk when they enter the food chain, not only to the ecosystem and to the agricultural economy but also consumers, including humans and animals as crop yields may be affected and exposure to the MC may lead to toxicological effects.

Uptake of MCs has been reported in Lactuca sativa (Codd et al. 1999), Solanum tuberosum L. Sinapis alba L. (McElhiney et al. 2001), Triticum aestivum, and Medicago sativa (Peuthert et al. 2007) under laboratory conditions. Exposure to MCs, either in single or as a crude extract, has caused various adverse effects in terrestrial plants including inhibited growth (Kós et al. 1995; Kurki-Helasmo and Meriluoto 1998; Chen et al. 2004), photosynthesis (Abe et al. 1996; Pflugmacher et al. 2007a), and germination (Pflugmacher et al. 2006, 2007a). Oxidative damage and subsequent elevation of the antioxidative enzymes caused by exposure to and uptake of MCs were shown in several studies (Pflugmacher et al. 2006, 2007a; Chen et al. 2014). Pflugmacher et al. (2007b) investigated the long-term effects (6 weeks) of a cyanobacterial crude extract containing $0.5 \mu \mathrm{g} / \mathrm{L}$ MC-LR on the growth and physiology of spinach under semi-field conditions, i.e. in garden soil in pots outside subjected to environmental factors. Morphological effects like growth inhibition and chlorosis as well as the generation of oxidative stress, as noted by elevated antioxidative stress enzyme expression and activity, could be observed.

From the existing literature, it is evident that exposure to MCs can cause adverse effects in plants under laboratory conditions, and thus, pose a threat to the quality and yield of crop plants. Furthermore, the uptake of these toxins in edible plants may have significant implications for consumers (McElhiney et al. 2001). However, little is known about the fate of these cyanotoxins in nature and their bioavailability to plants from soil. As the significance and frequency of cyanobacterial blooms in water supplies increases globally (Scholz et al. 2017) and the potential long-term effects are becoming apparent (Scholz et al. 2017; Omidi et al. 2018; Huisman et al. 2018), investigations into the persistence and degradation of cyanotoxins in the various ecosystem compartments, such as in soil become increasingly important.

Since bloom containing surface waters are used to sprayirrigate crop plants and soils possibly bind a portion of the cyanotoxins (Miller et al. 2001; Miller and Fallowfield 2001), investigating the bioavailability of MC-LR in soil to plants is a key aspect in evaluating the ecological threat posed by MC-LR. The persistence and bioavailability of MC-LR in soil and its influence on the growth of the legume Alfalfa (Medicago sativa L.) were studied, including the uptake of the toxins into the plant. The aim was to investigate and compare the bioavailability of MC-LR to Alfalfa from two structurally and chemically diverse soil types and determine the effects of the possible uptake of toxin under laboratory conditions via irrigation with water containing MC-LR and exposure to MC-LR previously adsorbed to the soils. In the present study, the adsorption of MC-LR onto two standard soils, one type silty sand and the other clayey loam, was investigated under laboratory conditions. The soils were chosen based on their difference in particle sizes, organic carbon contents, and $\mathrm{pH}$ values.

\section{Materials and methods}

\section{Test material and chemicals}

Alfalfa (M. sativa L.) seeds were purchased from Davert $\mathrm{GmbH}$. German standard soils were purchased from LUFASpeyer (Speyer, Germany), namely the 2.1 soil type, which is silty sand (uS) and the 6S soil type, which is clayey loam (tL). Typically, Alfalfa is grown on well-drained soils and non-clay-based soils, with a $\mathrm{pH}$ of 6.5 to 7.5 ; however, it was previously shown that heterocyclic peptides readily bind to clayey soils (Dashman and Stotzky 1984); and therefore, one silty sand and one clayey loam standard soil was selected for this investigation. The properties of the test soils are shown in Table 1. All experiments were performed with non-sterile, dry soil materials.

Purified, commercially available MC-LR was obtained from Axxora (Grünberg, Germany). The cell-free cyanobacterial crude extract (CE) was prepared using Microcystis aeruginosa MZ13 kindly donated by Prof. V. Vasconcelos (CIIMAR, Portugal). The extract was prepared by suspending $20 \mathrm{~g}$ dry weight (DW) in Milli- ${ }^{\circledR}{ }^{\circledR}$ water (Waters, Eschborn, Germany), stirred on ice for $15 \mathrm{~min}$, followed by ultrasonic treatment on ice for $15 \mathrm{~min}$, and then centrifugation at $22,000 \times g$ for $15 \mathrm{~min}$. The pellet was washed following the same procedure, and the resulting supernatants were pooled. This procedure was repeated five times. The $\mathrm{CE}$ was stored at $-80{ }^{\circ} \mathrm{C}$ until use. The toxin concentration of the crude extract was determined as specified in "MC-LR quantitative analysis" section. Toxin analysis revealed an 
Table 1 Properties of the two standard soils type 2.1 and $6 \mathrm{~S}$

\begin{tabular}{lll}
\hline & 2.1 (silty sand) & $6 \mathrm{~S}$ (clayey loam) \\
\hline Organic carbon in \% & $0.7 \pm 0.1$ & $1.7 \pm 0.2$ \\
Particles $<0.02 \mathrm{~mm} \mathrm{in} \mathrm{\%}$ & $7.9 \pm 1.1$ & $64.6 \pm 2.1$ \\
$\mathrm{pH}-\mathrm{value}\left(0.01 \mathrm{M} \mathrm{CaCl}_{2}\right)$ & $5.1 \pm 0.5$ & $7.2 \pm 0.1$ \\
Cation exchange capacity & $4.0 \pm 1.0$ & $22.0 \pm 6.0$ \\
(meq/100 g) & & \\
Water holding capacity $(\mathrm{g} / 100 \mathrm{~g})$ & $31.8 \pm 3.0$ & $39.6 \pm 5.0$ \\
Weight per volume (g/1000 mL) & $1430.0 \pm 67.0$ & $1330.0 \pm 96.0$ \\
Particle size (mm) distribution according to the German DIN (\%) \\
$<0.002$ & $2.8 \pm 0.8$ & $41.9 \pm 1.5$ \\
$0.002-0.006$ & $2.1 \pm 0.8$ & $10.5 \pm 0.9$ \\
$0.006-0.02$ & $3.0 \pm 0.7$ & $12.2 \pm 1.4$ \\
$0.02-0.063$ & $5.8 \pm 1.5$ & $14.3 \pm 2.3$ \\
$0.063-0.2$ & $27.2 \pm 3.0$ & $8.9 \pm 0.7$ \\
$0.2-0.63$ & $56.6 \pm 3.9$ & $8.9 \pm 0.4$ \\
$0.63-2.0$ & $2.5 \pm 0.6$ & $3.3 \pm 0.8$ \\
Soil type & Silty sand (uS) & Clayey loam (tL) \\
Particle size (mm) distribution according to the USDA (\%) \\
$<0.002$ & $2.9 \pm 0.8$ & $41.7 \pm 1.3$ \\
$0.002-0.05$ & $9.1 \pm 1.4$ & $36.1 \pm 2.2$ \\
$0.05-2.0$ & $88.0 \pm 1.0$ & $22.2 \pm 1.5$ \\
Soil type & Sand & Clay \\
\hline
\end{tabular}

MC-LR concentration of $168 \mathrm{mg} / \mathrm{L}$ in this extract. Localized particulate MC concentrations of up $1000 \mu \mathrm{g} / \mathrm{L}$ have been reported in lakes (Boyer 2008; Gkelis et al. 2015), therefore the concentrations of 100,500 and $1000 \mu \mathrm{g} / \mathrm{L}$ were selected for the treatments.

\section{Toxin recovery from soil}

\section{Concentration dependency batch adsorption}

Each soil type ( $0.5 \mathrm{~g}$ per independent replicate; $n=5)$ was suspended in $2 \mathrm{~mL}$ of aqueous pure MC-LR at concentrations of $100 \mu \mathrm{g} / \mathrm{L}(0.4 \mu \mathrm{g}$ MC-LR/g soil), $500 \mu \mathrm{g} / \mathrm{L}(2 \mu \mathrm{g}$ MC-LR/g soil), and $1000 \mu \mathrm{g} / \mathrm{L}$ (4 $\mu \mathrm{g}$ MC-LR/g soil) as well as the crude extract with a concentration of $168 \mathrm{mg} \mathrm{MC}-$ LR/L (672 $\mu \mathrm{g}$ MC-LR/g soil). For the negative controls, $0.5 \mathrm{~g}$ of the two types of soil were added to Milli- $\mathrm{Q}^{\circledR}$ water in triplicate. The suspensions were placed on an orbital shaker (Heidolph Vibramax 100, Schwabach, Germany), mixed at $600 \mathrm{rpm}$ for at least $2 \mathrm{~h}$ at room temperature, and incubated at $4{ }^{\circ} \mathrm{C}$ overnight resulting in a total contact time of $24 \mathrm{~h}$. Next, the suspension was centrifuged for $10 \mathrm{~min}$ at $10,000 \times g$, and the supernatant denoted as "media $M C-L R$ " was analysed for unbound MC-LR by LC-MS/MS as described in "MC-LR quantitative analysis" section. The remaining soil pellet was washed in Milli- $\mathrm{Q}^{\circledR}$ water by shaking for at least $3 \mathrm{~h}$ followed by centrifugation for $10 \mathrm{~min}$ at $10,000 \times g$. The supernatant denoted "water extract" was then analysed for unbound MC-LR. Afterwards, the residual soil pellet was suspended and extracted with $100 \%$ methanol shaking for $3 \mathrm{~h}$, incubated overnight at $4{ }^{\circ} \mathrm{C}$ and centrifuged for $10 \mathrm{~min}$ at $10,000 \times g$, followed by liquid chromatography-tandem mass spectrometry (LC-MS/MS) analysis of the unbound MC-LR referred to as the "methanol extract".

\section{Time dependency batch adsorption}

From each soil type, $50 \mathrm{~g}$ was added to $500 \mu \mathrm{g} / \mathrm{L}$ MC-LR (2.5 $\mu \mathrm{g}$ MC-LR/g soil) in quintuplicate. The suspensions were stirred at $600 \mathrm{rpm}$, and samples were taken at time intervals of 1,10 , and $30 \mathrm{~min}$ as well as 1, 4, 6, 24, 48, and $72 \mathrm{~h}$ and also after $7,14,28$, and 42 days. MC-LR in Milli- $Q^{\circledR}$ water was incubated under the same conditions as a positive control to evaluate natural dissolution. They were immediately extracted as described above analysing the media MC-LR, water, and methanol extracts for unbound MC-LR via LC-MS/MS.

\section{Bioavailability of MC-LR from soil to plants}

\section{Preparation of pre-spiked soil}

The two soil types (440 $\mathrm{g}$ each) were incubated with $500 \mu \mathrm{g} / \mathrm{L}$ MC-LR (2.5 $\mu \mathrm{g}$ MC-LR/g soil) in water by stirring (400 rpm) at room temperature for $24 \mathrm{~h}$ before centrifugation for $5 \mathrm{~min}$ at $4000 \times \mathrm{g}$. The supernatant was decanted, and the remaining soil was used for the plant exposures.

\section{Plant exposure}

Alfalfa (M. sativa L.) seeds were exposed either by planting in $55 \mathrm{~g}$ of pre-spiked (see "Preparation of pre-spiked soil" section) 2.1 (silty sand) or $6 \mathrm{~S}$ (clayey loam) soil $(2.5 \mu \mathrm{g} / \mathrm{g}$, $137.5 \mu \mathrm{g}$ total) in a falcon tube, or by watering with MC-LR spiked water $(55 \mathrm{~mL}$ of $500 \mu \mathrm{g} / \mathrm{L} \mathrm{MC}-\mathrm{LR}$ in total over the first seven days, i.e. $27.5 \mu \mathrm{g} \mathrm{MC}-\mathrm{LR}(n=5)$. Care was taken when watering the plants that only the soil close to the stem was watered (directly onto the soil) and not the splashed onto the leaves. All water remained in the pot and did not drain out. In parallel, three positive controls, which only contained the MC-LR pre-treated soil and was not sown with seeds, as well as three negative controls, which consisted of the soil incubated in water without toxin and sown with seeds, were conducted. The plants were watered every second day with tap water, which was tested and did not contain any toxin. Plants were grown under standardised conditions, i.e. $21{ }^{\circ} \mathrm{C}$, a humidity range of 60 to $70 \%$, and a day-night cycle of $14 \mathrm{~h}: 10 \mathrm{~h}$.

Plant height was measured every week for 3 weeks. Plant and soil samples were collected for toxin analysis after 
3 weeks. Alfalfa harvesting time is usually after 28 days; however, more often cutting is suggested in warm summers. Therefore, based on the conditions under which the plants were grown and their growth rate, it was decided to harvest after 21 days. Toxin uptake in the plants was determined in shoots and roots, and the height of exposed plants was compared to control plants. Toxin recovery from the soils (separated into three layers) and extracted with water and then methanol, as described before, after 3 weeks of growth was determined via LC-MS/MS.

\section{Plant extraction}

The fresh weight of the plant material was recorded before homogenization by overhead shaking in methanol for $18 \mathrm{~h}$ at room temperature. The samples were then centrifuged at $10,000 \times g$ for $10 \mathrm{~min}$. The pellets were re-homogenised in Milli- $\mathrm{Q}^{\circledR}$ water for $6 \mathrm{~h}$, followed by centrifugation at $10,000 \times g$ for $10 \mathrm{~min}$. The supernatants were combined and dried at $35{ }^{\circ} \mathrm{C}$ before resuspension in $100 \%$ methanol for LC-MS/MS analysis.

\section{MC-LR quantitative analysis}

MC-LR was quantified using liquid chromatography-tandem mass spectrometry (LC-MS/MS) on an Agilent 1200 high-performance liquid chromatography system coupled to a quadrupole Applied Biosystems 3500 system (Applied Biosystems, Darmstadt, Germany). An Agilent Eclipse Plus C18 (RP18, 4.6 $\times 50 \mathrm{~mm}, 3.5 \mu \mathrm{m})$ column was used for separation. Mobile phase A consisted of MS-grade water containing $0.1 \%(v / v)$ trifluoroacetic acid and solution B MS-grade acetonitrile containing $0.1 \%$ trifluoroacetic acid. Separation of $1 \mu \mathrm{L}$ of a sample (injection volume) was achieved at a flow rate of $0.4 \mathrm{~mL} / \mathrm{min}$ starting at $5 \%$ B was increased to $95 \%$ B over $6 \mathrm{~min}$ with a post-time of $3 \mathrm{~min}$ for re-equilibration. The linear gradient resulted in an elution time of $7.7 \mathrm{~min}$ for MC-LR. The column temperature was maintained at $40{ }^{\circ} \mathrm{C}$, and the injection volume was 10 $\mu \mathrm{L}$. Electrospray ionisation (ESI) in multiple reaction-monitoring (MRM) mode was performed in positive mode. The capillary voltage was set at $5 \mathrm{kV}$, the drying gas was set at $8 \mathrm{~L} / \mathrm{min}$ at $320^{\circ} \mathrm{C}$, and the sheath gas at a flow rate of $11 \mathrm{~L} / \mathrm{min}$ at $380^{\circ} \mathrm{C}$. The MC-LR parent compound and its correspondent fragment ions were monitored at the massto-charge ratios $995.5 \rightarrow 155,135$, and $213 \mathrm{~m} / \mathrm{z}$ using 80,86 and $75 \mathrm{~V}$ as settings for the collision energy per each respective fragment (Esterhuizen-Londt et al. 2017).

\section{Statistical analysis}

Statistical analysis to test for significance was performed on IBM SPSS Statistics 25. One-way analysis of variance (ANOVA) followed by a Tukey's test at $P<0.05$ was used when the data sets satisfied the requirements for normality according Shapiro-Wilk and homogeneity according to Levene's test. If a data set proved to be non-parametric, the Kruskal-Wallis one-way ANOVA and multiple comparisons of mean ranks was used to test for differences between different exposures and controls $(P<0.05)$.

\section{Results and discussion}

\section{Results}

\section{Toxin recovery from soil}

Concentration dependency batch adsorption The percentages of free unbound toxin remaining in the exposure media of silty sand $(2.1$ soil) were $73.0 \% \pm 0.3 \%$ after incubation with $100 \mu \mathrm{g} \mathrm{MC}-\mathrm{LR} / \mathrm{L}, 73.3 \% \pm 1.0 \%$ with $500 \mu \mathrm{g} / \mathrm{L}$, and
Fig. 1 The percentage of free MC-LR detectable in silty sand and clayey loam media, after water wash, and methanol extraction, respectively, after $24 \mathrm{~h}$ exposure to MC-LR from a CE or pure MC-LR at different concentrations. Data represent the mean percentages \pm standard deviation $(n=5)$

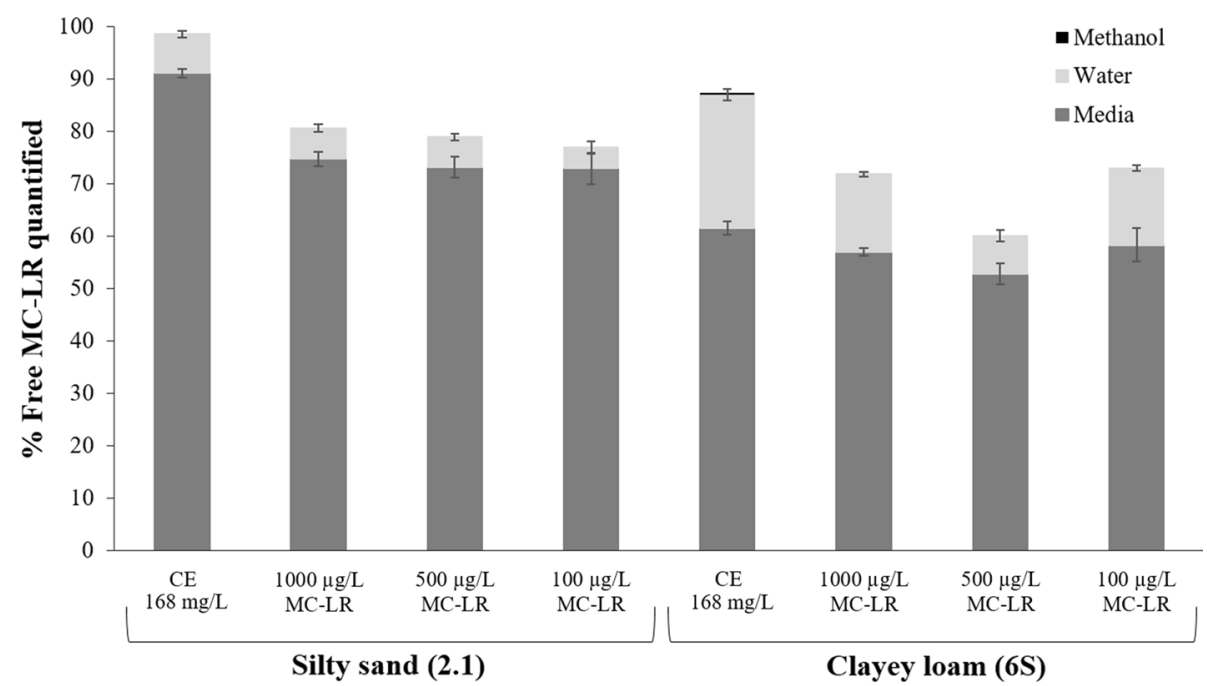


$74.8 \% \pm 1.3 \%$ with $1000 \mu \mathrm{g} / \mathrm{L}$ (Fig. 1); thus, the recovery was not dose-dependent $(P>0.05)$. From the water wash, $4.0 \% \pm 1.2 \%, 5.7 \% \pm 0.7 \%$, and $5.9 \% \pm 0.7 \%$ of free toxin could be detected from the 2.1 soil type after incubation with 100,500 , and $1000 \mu \mathrm{g} / \mathrm{L}$ MC-LR, respectively $(P>0.05)$. No MC-LR was detected after methanol extraction from the 2.1 soil. The total percentages of free MC-LR therefore amounted to $77.0 \% \pm 3.9 \%, 79.0 \% \pm 1.7 \%$, and $80.7 \% \pm 1.0 \%$ of MC-LR from exposure to 100,500 , and $1000 \mu \mathrm{g} / \mathrm{L}$ MC-LR, respectively. With the CE, the percentages quantified from soil type 2.1 was $91.2 \% \pm 0.8 \%$, $7.5 \% \pm 0.6 \%$, and $0 \%$ from the media, and with the water wash, and methanol extraction; amounting to a total percentage of $98.7 \% \pm 1.3 \%$.

From the clayey loam $6 \mathrm{~S}$ soil, $58.3 \% \pm 3.2 \%, 52.9 \% \pm 2.0$, and $57.1 \% \pm 0.8 \%$ of unbound MC-LR was quantified in the media after exposure for $24 \mathrm{~h}$ to 100,500 , and $1000 \mu \mathrm{g} / \mathrm{L}$ MC-LR, respectively. Total free toxin quantified from the $6 \mathrm{~S}$ ranged from 60.1 to $73.0 \%$. Compared to the 2.1 silty sand, less free toxin could be detected in the clayey loam soil $6 \mathrm{~S}$, i.e. $31.7 \% \pm 8.3 \%$ of the total MC-LR added was detected after $24 \mathrm{~h}$ in $6 \mathrm{~S}$ compared to $21.1 \% \pm 1.9 \%$ which was not detected from the 2.1 soil. In the $\mathrm{H}_{2} \mathrm{O}$ extract more MC-LR was recovered from the clayey loam $6 \mathrm{~S}$ than from silty sand 2.1. On average, $12.2 \% \pm 2.6 \%$ of MC-LR adsorbed to the $6 \mathrm{~S}$ soil but could be recovered in the $\mathrm{H}_{2} \mathrm{O}$ extract. With 2.1 soil, only $5.2 \% \pm 0.7 \%$ was recovered by water. In total, around $68.3 \% \pm 4.7 \%$ of free MC-LR was detected from soil $6 \mathrm{~S}$; therefore, approx. $32 \%$ must have remained adsorbed to the soil. For the 2.1 soil type, $78.9 \% \pm 1.78 \%$ of the MC-LR was recovered; thus, approx. $21 \%$ of the toxin remained in the soil. With exposure to the CE, free MC-LR recovered from $6 \mathrm{~S}$ soil amounted to $61.6 \pm 1.3 \%, 25.6 \pm 1.1 \%$, and $0.4 \pm 0.1 \%$ for the media, water wash, and methanol extraction, respectively.

Time dependency The total free recoverable MC-LR detectable with time in the $6 \mathrm{~S}$ and 2.1 soils is shown in Fig. 2. In the $6 \mathrm{~S}$ soil, for the first $6 \mathrm{~h}$, the percentage of free recoverable MC-LR remained constant $(P>0.05$, Fig. 2 insert). The percentage for free MC-LR decreased to $82 \%$ after $24 \mathrm{~h}, 56 \%$ after $48 \mathrm{~h}$, and $47 \%$ after $72 \mathrm{~h}$. After the first $6 \mathrm{~h}$, the percentage of free toxin from $6 \mathrm{~S}$ soil was significantly lower than the control $(P<0.05)$.

In soil 2.1 (Fig. 2 insert), for the first $6 \mathrm{~h}$ the recovery percentages for MC-LR were stable at $99 \% \pm 1 \%(P>0.05)$ free MC-LR. After $24 \mathrm{~h}$, the percentage declined to $92.8 \pm 5.6 \%$, which continued to decrease after $48 \mathrm{~h}$ to $83.0 \% \pm 1.4 \%$, and after $72 \mathrm{~h}, 75.9 \% \pm 1.3 \%$ of MC-LR could be recovered (Fig. 2). After $72 \mathrm{~h}$, the decrease in recoverable MC-LR in the soil compared to the control in water was significantly lower $(P<0.05)$. After seven days, $22.7 \% \pm 0.6 \%$ of MC-LR was detected in the media, after which time point no MC-LR was further detected. As seen from Fig. 2, the percentages for free MC-LR, and therefore, the adsorption capacities between the two soils are significantly different for all sampling points after $4 \mathrm{~h}$.

\section{Bioavailability of MC-LR from soil to plants}

The overall plant length of $M$. sativa was not affected by the presence of MC-LR in the 2.1 soil as pre-treated soil or via exposure through irrigation over the entire exposure periods compared to the unexposed control $(P>0.05)$
Fig. 2 The percentage of total free MC-LR from an initial concentration of $500 \mu \mathrm{g} / \mathrm{L}$ that could be detected with time in the two soil types. Data represent the mean percentages \pm standard deviation $(n=5)$. Insert shows data from 0 to $6 \mathrm{~h}$

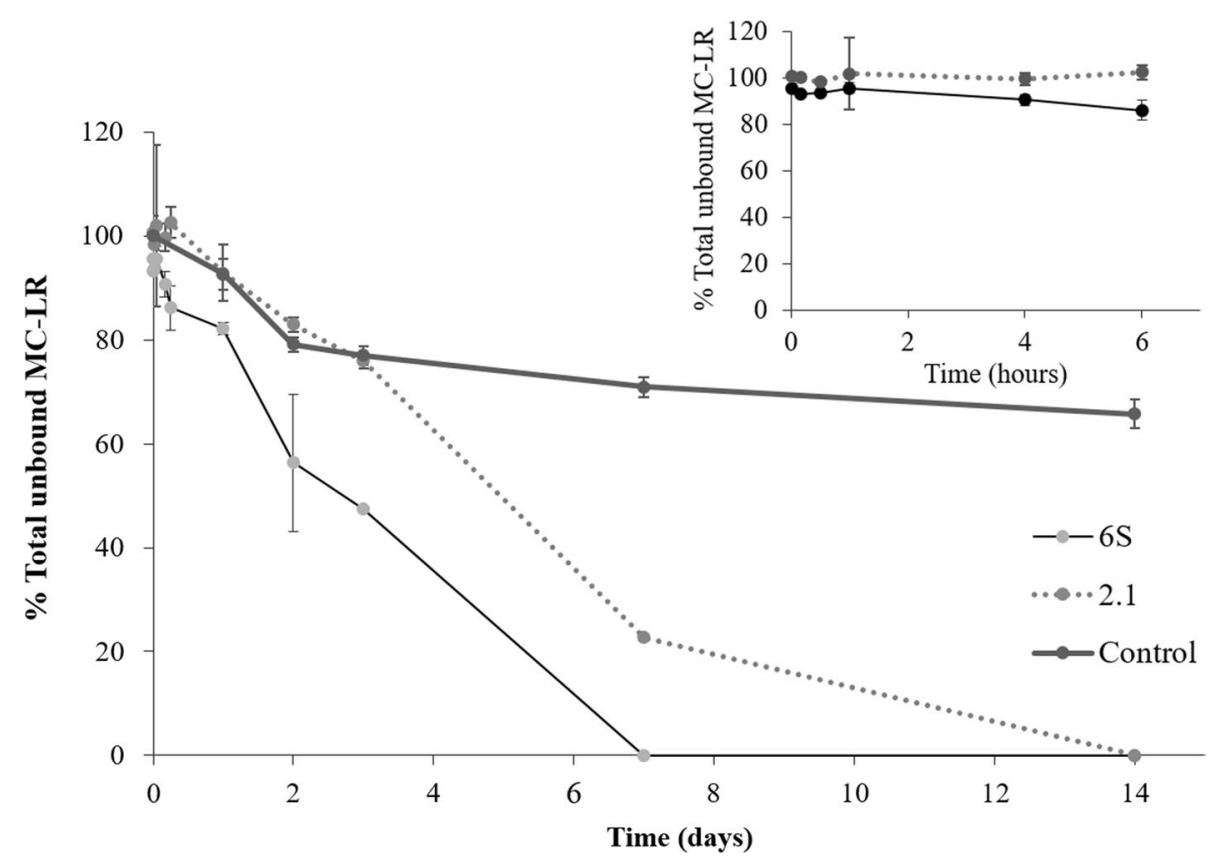


(Fig. 3a). However, the germination of Alfalfa grown in $6 \mathrm{~S}$ soil exposed to MC-LR through irrigation was significantly delayed compared to the control with no growth after the first seven days $(P<0.001)$. The Alfalfa plants irrigated with MC-LR in the $6 \mathrm{~S}$ soil remained significantly smaller compared to the control after both 14 days $(P=0.015)$ and 21 days $(P<0.001)$. With exposure to $6 \mathrm{~S}$ soil pre-treated with MC-LR, no significant difference in plant height was evident compared to the control $(P>0.05)$ (Fig. 3b).

After 3 weeks of exposure, significantly more MC-LR remained in the 2.1 soil controls, compared to the exposure of 2.1 soils in which Alfalfa was grown $(P<0.05)$ (Fig. $4 a)$. In the middle and bottom layers, significantly less MC-LR remained in the exposed 2.1 pre-treated soil compared to the top layer $(P<0.001)$. The amounts of MC-LR distributed within the three layers of the control remained equal between in the pre-treated 2.1 soil $(P>0.05)$. With irrigation of the Alfalfa in the 2.1, most of the MC-LR was retained in the top layer for both the exposures and controls.

Interestingly, more MC-LR remained in the pre-treated expose $6 \mathrm{~S}$ soil after 3 weeks of Alfalfa cultivation compared to control $(P<0.05)$. With exposure via irrigation in $6 \mathrm{~S}$ soil, the same total amount of MC-LR remained after 3 weeks compared to the control (Fig. 4b).

After 3 weeks of exposure, more MC-LR was detected in the Alfalfa plants cultivated in 2.1 soil compared to the $6 \mathrm{~S}$ soil (Fig. 5). Alfalfa plants cultivated in the 2.1 soil contained larger amounts of MC-LR in the roots compared to the shoots. With the cultivation of the Alfalfa on pre-treated $6 \mathrm{~S}$, more MC-LR was detected in the roots compared to the shoots; however, more MC-LR was detected in the shoots compared to the roots with irrigation. In the negative controls, MC-LR was not detected in any of the soil layers nor the different parts of the Alfalfa plants.

\section{Discussion}

The present study aimed to investigate and compare the bioavailability of MC-LR to Alfalfa from distinct soil types and how uptake would affect Alfalfa. In general,

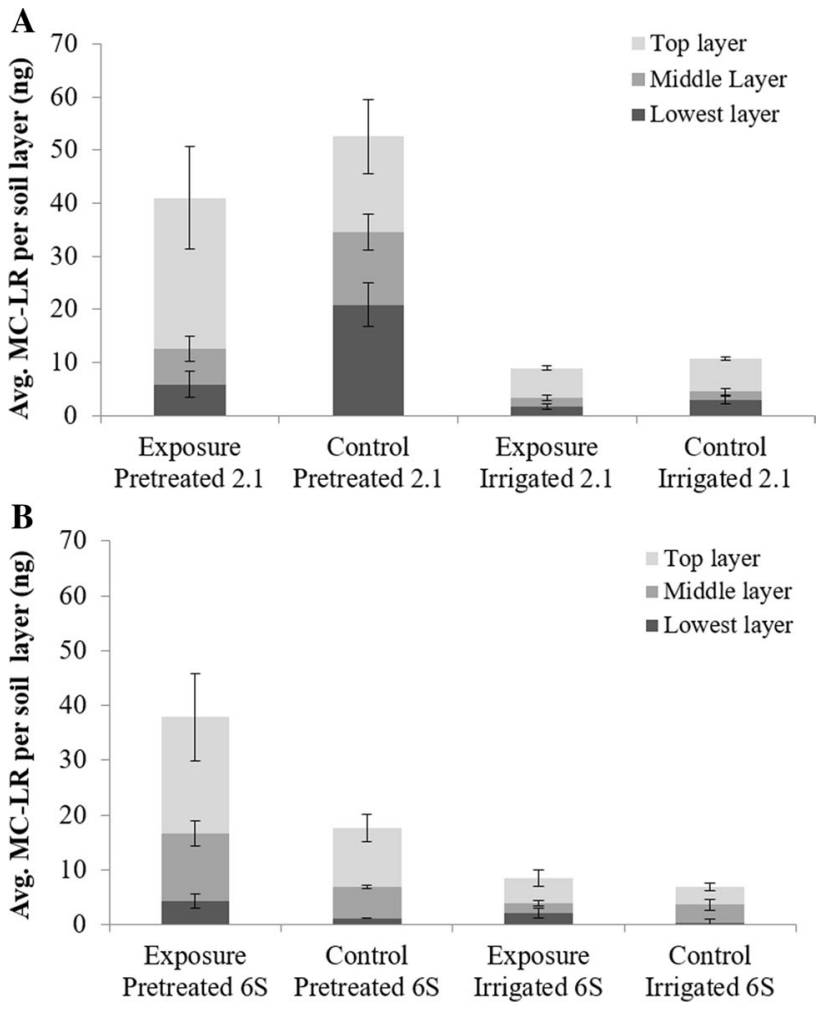

Fig. 4 Free MC-LR detected in the three soil layers after 3 weeks of $M$. sativa (Alfalfa) growth in a 2.1 soil and b $6 \mathrm{~S}$ soil. Data represent average total MC-LR per soil layer \pm standard deviation $(n=5)$

it was found that with clayey loam less MC-LR was available for uptake, and the growth of Alfalfa was only affected in the clayey loam with MC LR exposure via irrigation. MC-LR was taken up by Alfalfa grown in both soil types and by exposure via both methods used. Remarkably, more MC-LR remained in the silty sand after 3 weeks; yet, more MC-LR was taken up by the Alfalfa grown in the silty sand, with a larger concentration in the roots compared to the shoots.
Fig. 3 Plant height of Alfalfa (M. sativa) grown in a 2.1 and b 6S standard soil; the exposure was either via pre-MC-LRexposed soil or irrigated with MC-LR containing water for 3 weeks. Data represent average plant height in centimetre \pm standard deviation $(n=5)$
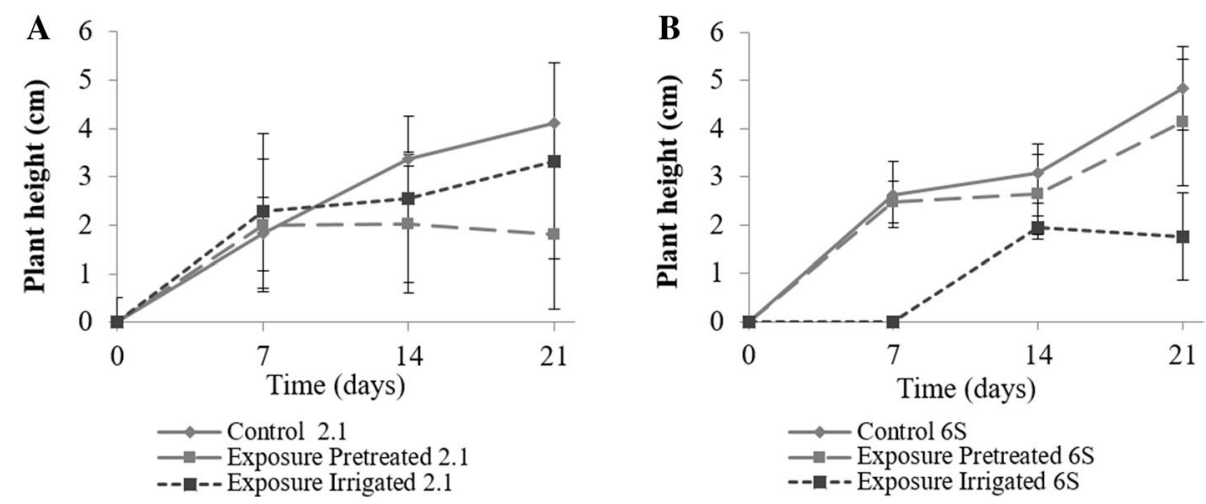


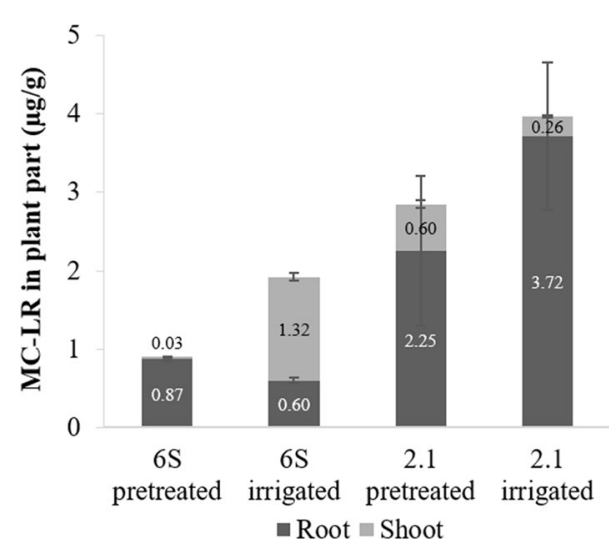

Fig. 5 Free MC-LR detected in Alfalfa after 3 weeks of exposure to MC-LR either from pre-contaminated soil or via irrigation. Data represent average MC-LR concentration in $\mu \mathrm{g} / \mathrm{g}$ taken up \pm standard deviation $(n=5)$

\section{Toxin recovery from soil}

In the current study, two German standard soils type, i.e. silty sand (2.1) versus clayey loam (6S), were used in batch analysis experiments to compare the adsorption capacities at different concentrations of MC-LR. The batch adsorption technique describes the retention of a substance in the soil at various concentrations. It explains and predicts the mobility of a substance in the environment. Although this technique has disadvantages like overestimating the adsorption to the soil, it is easy to use and gives an indication of contaminant behaviour in the soil. The total amount of toxin added could not be recovered after $24 \mathrm{~h}$ (Fig. 1), and as seen with the time study, the amount of detectable toxin decreased with time (Fig. 2). The quantifiable percentage of MC-LR after $24 \mathrm{~h}$ was significantly different for the two soils used, with a lower percentage from 6 S. Jones et al. (1994) reported a three-day lag or conditioning phase before microbial degradation of MC-LR occurred. Thus, the loss of toxin could be attributed to adsorption onto soil because microbial degradation is unlikely to have happened within the $24 \mathrm{~h}$ incubation period. The percentages of MC-LR detected and therefore, the toxin adsorption (bound residue) onto the individual soils were not dose-dependent.

The clayey loam 6S soil had a higher adsorption capacity for MC-LR than the silty sand 2.1 soil. The $6 \mathrm{~S}$ soil has a higher organic carbon content, smaller average particle size, and higher $\mathrm{pH}$-value (Table 1). It was previously demonstrated that clay and organic carbon are essential in binding organic compounds in soils (Miller et al. 2001), possibly explaining the difference seen in binding between the two soil types. Clay particles are most likely the active binding components in the soil, as opposed to the organic carbon content (Miller and Fallowfield 2001). Morris et al. (2000) showed that clay minerals could scavenge MC-LR from solution. Chen et al. (2006a) showed that the sorption behaviour of microcystins does not only depend on the total organic matter contents but also the content of clay in the soils. They also concluded that soil type and soil clay content are the main factors influencing the adsorption of MCs in soils. Chen et al. (2006a, b) proposed that the adsorption mechanisms of microcystins to soils are not only physical sorption but also chemical binding with metal ions on the surface of soil particles. Thus, the clay content is more important than the content of organic compounds in influencing the toxin adsorption because microcystins can chelate with the metal ions in clay.

It was previously reported that at higher $\mathrm{pH}$ values, MC-LR would be hydrophilic and hence more likely to stay in the liquid phase of the batch study, as opposed to adsorbing soil particles (Miller et al. 2001). However, in the current study, the $6 \mathrm{~S}$ soil with a higher $\mathrm{pH}$ retained a more significant percentage of MC-LR compared to the 2.1 soil, which has a lower $\mathrm{pH}$. Therefore, clay particles and organic carbon content possibly play a more substantial part in adsorption than $\mathrm{pH}$. When considering the total amount of MC-LR detected from the media and wash fraction of $6 \mathrm{~S}$ and the improbability of microbial degradation, approx. $32 \%$ remained adsorbed to the $6 \mathrm{~S}$ soil. As with 2.1 soil, approx. $21 \%$ of microcystin possibly remained in the soil.

In an attempt to quantify the bound fraction of toxin in the soils, a methanol extraction was performed; however, this yielded no results. The difficulties of microcystin extraction from sediments have been mentioned before (Eynard et al. 2000; Tsuji et al. 2001). All conventional solvents and extraction procedures (Lawton et al. 1994, 1995; Barco et al. 2005) failed to extract microcystins efficiently. This may indicate that MCs bind strongly to soils and sediments, and as Chen et al. (2006a, b) suggested MCs in soils and sediments undergo not only physical adsorption but also chemical bonding. Therefore, an extraction with 3:2 solution of $0.1 \mathrm{M}$ EDTA and $70 \%$ methanol was attempted as suggested by Chen et al. (2006b) as the solution is more efficient than methanol; however, no toxin could be further extracted.

With a microcystin crude, extract (CE) the total detectable percentages were $98.68 \%$ for the 2.1 soil and $87.57 \%$ for $6 \mathrm{~S}$. The overall percentage of unbound CE MC-LR quantified from the soil 2.1 were up to $18 \%$ and for $6 \mathrm{~S}$ up to $19 \%$ higher compared to using pure toxin. It is possible that other microcystin variants in the crude extract, which show a different adsorption behaviour (Chen et al. 2006a) could have outcompeted MC-LR for binding sites on the soil particles allowing the recovery of more unbound MC-LR.

When investigating the adsorption over time, it was evident that more unbound MC-LR could be quantified from the 2.1 soil at all time points compared to the $6 \mathrm{~S}$. In total, approx. $90 \%$ of the unbound toxin could be quantified from $6 \mathrm{~S}$ soil within the first $6 \mathrm{~h}$. After this period, decreased 
percentages of free MC-LR were observed with time until day seven when no more unbound MC-LR could be quantified from the $6 \mathrm{~S}$ soil. For the 2.1 soil, the quantification percentage of free MC-LR in total was around 100\% until $6 \mathrm{~h}$. Following this time point, decreased percentages of the unbound toxin were observed as well but at a slower rate compared to $6 \mathrm{~S}$. The variance can be accounted for by the differences in absorption properties of the two soils as also seen from the $24 \mathrm{~h}$ batch experiment where MC-LR was not adsorbed as well to the silty sand compared to the clayey loam.

It was previously reported that microbial degradation of MC-LR only occurred after a lag phase of 3 to 8 days in water samples (Gupta and Gajbhiye 2004). However, it should be noted that MC-LR dissipation due to microbial degradation was observed to be faster in soils with high organic carbon content (Chen et al. 2006a). Microbial degradation in the batch analysis was also excluded by Miller and Fallowfield (2001) for at least the first $52 \mathrm{~h}$. Chen et al. (2006a, b) calculated a half time for MC-LR ranging from 6.0 to 17.1 days. Miller et al. (2001) also excluded the loss of toxin in the batch analysis. Therefore, the reduced MC-LR recovery rates in the media and in total can be ascribed to adsorption onto soil until 48 or $72 \mathrm{~h}$.

\section{Plant exposure}

In the present study, Alfalfa was exposed via soil previously treated with MC-LR as well as via irrigation with the toxin. When considering the $24 \mathrm{~h}$ batch exposure, $26.8 \%$ of the MC-LR remained in the 2.1 soil and $47.1 \%$ in the $6 \mathrm{~S}$ soil with exposure to $500 \mu \mathrm{g} / \mathrm{L}$, which equates to Alfalfa exposed to $36.6 \mu \mathrm{g}$ in 2.1 soil and $64.8 \mu \mathrm{g}$ in $6 \mathrm{~S}$ soil. It should also be considered that for 2.1 soil, $5.7 \%$ of the MC-LR percentage remaining in the soils was available in the water wash $(7.9 \mu \mathrm{g})$ and $7.2 \%(9.8 \mu \mathrm{g})$ for $6 \mathrm{~S}$ soil and thus readily available to the plants as soluble toxin. Via irrigation, the plants were exposed to $27.5 \mu \mathrm{g}$ of MC-LR in total, which is considerably less than the amounts hypothetically remaining in the pre-spiked soil; however, all was in soluble form and at the soil surface level. When considering how much soluble MC-LR remained in the soil after 3 weeks of Alfalfa cultivation (Fig. 4), much less was detected in the irrigated soils. It seems that with the pre-spiked soils, adsorbed MC is not readily available for plants possibly due to chemical bonding, and therefore, more toxin stayed in the soil (Fig. 4). From 2.1 soil, higher concentrations of toxin could be recovered with both treatments, although less toxin adsorbed during the batch analysis and samples were irrigated with less toxin.

Overall, more toxin could be detected in samples where no plant was grown (expect soil $6 \mathrm{~S}$ with $M$. sativa). This could be interpreted as removal of the toxin in the soil due to an uptake in the plants. In the controls of the pre-spiked treatments, much less toxin could be recovered after 3 weeks from the $6 \mathrm{~S}$ soil. This may be due to the higher organic carbon content in $6 \mathrm{~S}$ soil, and therefore, a faster microbial degradation as has been shown by Chen et al. (2006a). In the irrigated controls, less MC-LR was recovered after 3 weeks compared to the controls of pre-spiked treatment, signifying that irrigated plants were exposed to less toxin or rapid degradation at the soil surface level within 3 weeks. However, only the plant height of Alfalfa irrigated in $6 \mathrm{~S}$ was significantly inhibited. Several studies have shown that terrestrial plants exposed to microcystins suffer inhibited plant growth (Pflugmacher et al. 2007a; Kós et al. 1995), which could negatively influence crop quality and yield in reality (Chen et al. 2004). Plausibly these adverse effects can be due to the toxic effect of MC-LR at a physiological level such as oxidative stress, reduced photosynthetic capacity, metabolic changes, and disturbances of signal pathways (Kós et al. 1995; Pflugmacher et al. 2007a; Abe et al. 1996). The difference in plant growth seen between 2.1 and 6S cannot be attributed to the soil properties as the controls grew equally well in both soils and thus can only be attributed to the amount of MC-LR that was bioavailable to the plants from each soil type.

Interestingly, even though adverse effects were only observed on the growth and germination with irrigation in $6 \mathrm{~S}$ soil, around $50 \%$ less toxin was detectable in Alfalfa grown in $6 \mathrm{~S}$ soil compared to Alfalfa grown in 2.1 soil. Kurki-Helasmo and Meriluoto (1998) also observed high concentrations $(5.3 \mathrm{mg} / \mathrm{kg})$ of toxin in healthy-looking mustard plants. It was unexpected that in plants grown on the silty sand and therefore exposed to less toxin, higher concentrations of MC could be detected. Furthermore, despite less toxin remaining in the irrigated controls suggesting lower exposure, more MC-LR was taken up by Alfalfa exposed via irrigation for both soil types, suggesting that the dissolved toxin was more bioavailable for the plants for bioaccumulation via irrigation than from soil.

Alfalfa is commonly used as fodder for livestock such as cows and therefore could serve as an entry point for MC-LR into the food chain with humans as the ultimate consumers. The Alfalfa grown in the $6 \mathrm{~S}$ soil type and irrigated with MC-LR spiked water poses the most considerable exposure risk to grazers as this treatment group contained the most toxin in the edible parts (shoots). However, after 3 weeks, the alfalfa plants are still considered seedlings, and even though most of the MC-LR taken up from the 2.1 soil remained in the roots, the toxin could be transported to the shoots as the plants grow. Differences in cyanotoxin uptake and distribution within the plant appendages were previously shown (Esterhuizen-Londt and Pflugmacher 2019). Therefore, it is likely that at the seedling growth stage, nutrients essential for growth are prioritised for transport from nutrient-poor 
soil such as the 2.1 soil type to support growth. Longerterm experiments are needed to understand the distribution of the toxin within the plants fully and to thoroughly assess the ecological risk of exposure to livestock through feeding.

The difference in bioavailability of MC-LR from two soil types is presented in the present study and exposure via two routes (i.e. pre-spiked and irrigation) resulted in different physiological effects in Alfalfa as well as the uptake of MC-LR. Not only does the contamination of soil with cyanobacterial toxin pose a threat to our food stocks, but they can also serve as a pool from which other ecosystem compartments can be contaminated as the toxin can be washed back to waterbodies through leaching, runoff, and drainage. Further research is needed to understand the type and mechanism of binding and to test the stability of the absorption of MC-LR to soils.

Acknowledgements We would like to thank Prof. V. Vasconcelos (CIIMAR, Portugal) for kindly donating Microcystis aeruginosa MZ13.

Author's contribution ME, NS, and SP: conceptualization; SP, NS: methodology; NS: formal analysis and investigation; ME: data analysis; ME: writing — original draft preparation; ME, SP, NS: writing — review and editing; SP: funding acquisition; SP: resources; SP: supervision.

Funding Open Access funding provided by University of Helsinki including Helsinki University Central Hospital. This research did not receive any specific grant from funding agencies in the public, commercial, or not-for-profit sectors. Open access funding provided by the University of Helsinki, including Helsinki University Central Hospital. No funding was received to assist with the preparation of this manuscript.

\section{Compliance with ethical standards}

Conflict of interest The authors declare that there is no conflict of interest regarding the publication of this article.

Ethical approval This article does not contain any studies with human participants or animals performed by any of the authors.

Open Access This article is licensed under a Creative Commons Attribution 4.0 International License, which permits use, sharing, adaptation, distribution and reproduction in any medium or format, as long as you give appropriate credit to the original author(s) and the source, provide a link to the Creative Commons licence, and indicate if changes were made. The images or other third party material in this article are included in the article's Creative Commons licence, unless indicated otherwise in a credit line to the material. If material is not included in the article's Creative Commons licence and your intended use is not permitted by statutory regulation or exceeds the permitted use, you will need to obtain permission directly from the copyright holder. To view a copy of this licence, visit http://creativecommons.org/licenses/by/4.0/.

\section{References}

Abe T, Lawson T, Weyers JDB (1996) Microcystin-LR inhibits photosynthesis of Phaseolus vulgaris primary leaves: implications for current spray irrigation practice. New Phytol 133:651-658. https ://doi.org/10.1111/j.1469-8137.1996.tb01934.x

Barco M, Lawton LA, Rivera J, Caixach J (2005) Optimization of intracellular microcystin extraction for their subsequent analysis by high-performance liquid chromatography. J Chromatogr A 1074:23-30. https://doi.org/10.1016/j.chroma.2005.03.087

Bouaïcha N, Corbel S (2016) Cyanobacterial toxins emerging contaminants in soils: a review of sources, fate and impacts on ecosystems, plants and animal and human health. In: Larramendy M, Soloneski S (eds) Soil contamination-current consequences and further solutions. InTech, Rijeka, pp 105-126

Boyer G (2008) Cyanobacterial toxins in New York (Chapter 7). In: Hudnell HK (ed) Cyanobacterial harmful algal blooms: state of the science and research needs. Springer, New York, pp 153-166

Chen W, Gan NQ, Song LR (2004) Photodegradation dynamics of pure microcystin variants with illumination of fixed wavelength UV-lights. Acta Chim Sin 62:142-147. https://doi.org/10.1038/ sj.cr.7290254

Chen W, Li L, Gan N, Song L (2006a) Optimization of an effective extraction procedure for the analysis of microcystins in soils and lake sediments. Environ Pollut 143:241-246. https://doi. org/10.1016/j.envpol.2005.11.030

Chen W, Song L, Gan N, Li L (2006b) Sorption, degradation and mobility of microcystins in Chinese agriculture soils: risk assessment for groundwater protection. Environ Pollut 144:752-758. https://doi.org/10.1016/j.envpol.2006.02.023

Chen J, Song L, Dai J, Gan N, Liu Z (2014) Effects of microcystins on the growth and the activity of superoxide dismutase and peroxidase of rape (Brassica napus L.) and rice (Oryza sativa L.). Toxicon 43:393-400. https://doi.org/10.1016/j.toxicon.2004.01.011

Codd GA, Metcalf JS, Beattie KA (1999) Retention of Microcystis aeruginosa and microcystin by salad lettuce (Lactuca sativa) after spray irrigation with water containing cyanobacteria. Toxicon 37:1181-1185. https://doi.org/10.1016/S0041-0101(98)00244-X

Contardo-Jara V, Schwanemann T, Pflugmacher S (2014) Uptake of a cyanotoxin, $\beta-N$-methylamino-L-alanine, by wheat (Triticum aestivum). Ecotoxicol Environ Saf 104:127-131. https://doi. org/10.1016/j.ecoenv.2014.01.039

Contardo-Jara V, Schwanemann T, Esterhuizen-Londt M, Pflugmacher $\mathrm{S}$ (2018) Protein association of $\beta$ - $N$-methylamino-L-alanine in Triticum aestivum via irrigation. Food Addit Contam Part A Chem Anal Control Expo Risk Assess 35(4):731-773. https:// doi.org/10.1080/19440049.2018.1427283

Dashman T, Stotzky G (1984) Adsorption and binding of peptides on homoionic montmorillonite and kaolinite. Soil Biol Biochem 16:51-55. https://doi.org/10.1016/0038-0717(84)90125-1

Esterhuizen-Londt M, Pflugmacher S (2019) Vegetables cultivated with exposure to pure and naturally occurring $\beta-N$-methylaminoL-alanine (BMAA) via irrigation. Environ Res 169:357-361. https ://doi.org/10.1016/j.envres.2018.11.030

Esterhuizen-Londt M, Hertel S, Pflugmacher S (2017) Uptake and biotransformation of pure commercial microcystin-LR versus microcystin-LR from a natural cyanobacterial bloom extract in the aquatic fungus Mucor hiemalis. Biotechnol Lett 39(10):15371545. https://doi.org/10.1007/s10529-017-2378-2

Eynard F, Mez K, Walther JL (2000) Risk of cyanobacterial toxins in Riga waters (Latvia). Water Res 34:2979-2988. https://doi. org/10.1016/S0043-1354(00)00042-7

Gkelis S, Lanaras T, Sivonen K (2015) Cyanobacterial toxic and bioactive peptides in freshwater Bodies of Greece: Concentrations, occurrence patterns, and implications for human health. Mar Drugs 13:6319-6335. https://doi.org/10.3390/md13106319

Gupta S, Gajbhiye VT (2004) Adsorption-desorption, persistence and leaching behavior of thifluzamide in alluvial soil. Chemosphere 57:471-480. https://doi.org/10.1016/j.chemosphere.2004.06.033 
Huisman J, Codd GA, Paerl HW, Ibelings BW, Verspagen JMH, Visser PM (2018) Cyanobacterial blooms. Nat Rev Microbiol 16:471483. https://doi.org/10.1038/s41579-018-0040-1

Jones GJ, Bourne DG, Blakeley RL, Doelle H (1994) Degradation of the cyanobacterial hepatotoxin microcystin by aquatic bacteria. Nat Toxins 2:228-235. https://doi.org/10.1002/nt.2620020412

Kós P, Gorzó G, Surányi G, Borbély G (1995) Simple and efficient method for isolation and measurement of cyanobacterial hepatotoxins by plant tests (Sinapis alba L.). Anal Biochem 225:49-53. https://doi.org/10.1006/abio.1995.1106

Kurki-Helasmo K, Meriluoto J (1998) Microcystin uptake inhibits growth and protein phosphatase activity in mustard (Sinapis alba L.) seedlings. Toxicon 36:1921-1926. https://doi.org/10.1016/ s0041-0101(98)00114-7

Lawton LA, Edwards C, Codd GA (1994) Extraction and high-performance liquid chromatographic method for the determination of microcystins in raw and treated waters. Analyst 119(7):15251530. https://doi.org/10.1039/an9941901525

Lawton LA, Edwards C, Beattie KA, Pleasance S, Dear GJ, Codd GA (1995) Isolation and characterization of microcystins from laboratory cultures and environmental samples of Microcystis aeruginosa and from an associated animal toxicosis. Nat Toxins 3:50-57. https://doi.org/10.1002/nt.2620030110

Lee J, Lee S, Jiang X (2017) Cyanobacterial toxins in freshwater and food: Important sources of exposure to humans. Annu Rev Food Sci Technol 8:281-304. https://doi.org/10.1146/annurevfood-030216-030116

McElhiney J, Lawton LA, Leifert C (2001) Investigations into the inhibitory effects of microcystins on plant growth, and the toxicity of plant tissues following exposure. Toxicon 39:1411-1420. https://doi.org/10.1016/s0041-0101(01)00100-3

Miller MJ, Fallowfield HJ (2001) Degradation of cyanobacterial hepatotoxins in batch experiments. Water Sci Technol 43:229-232. https://doi.org/10.2166/wst.2001.0745

Miller MJ, Critchley MM, Hutson J, Fallowfield HJ (2001) The adsorption of cyanobacterial hepatotoxins from water onto soil during batch experiments. Water Res 35:1461-1468. https://doi. org/10.1016/s0043-1354(00)00419-x

Morris RJ, Williams DE, Luu HA, Holmes CFB, Andersen RJ, Calvert SE (2000) The adsorption of microcystin-LR by natural clay particles. Toxicon 38:303-308. https://doi.org/10.1016/S0041 -0101(99)00149-X

Omidi A, Esterhuizen-Londt M, Pflugmacher S (2018) Still challenging: the ecological function of the cyanobacterial toxin microcystin-what we know so far. Toxin Rev 37:87-105. https://doi. org/10.1080/15569543.2017.1326059

Orr PT, Jones GJ (1998) Relationship between microcystin production and cell division rates in nitrogen-limited Microcystis aeruginosa cultures. Limnol Oceanogr 43:1604-1614. https:// doi.org/10.4319/lo.1998.43.7.1604

Peuthert A, Chakrabarti S, Pflugmacher S (2007) Uptake of microcystins-LR and -LF (cyanobacterial toxins) in seedlings of several important agricultural plant species and the correlation with cellular damage (lipid peroxidation). Environ Toxicol 22:436-442. https://doi.org/10.1002/tox.20266

Peuthert A, Kun L, Baik S, Pflugmacher S (2015) Transfer of cyanobacterial toxins into edible plants via irrigation with lake watera Chinese case study. AJAME 1:101. https://doi.org/10.14437/ AJAME-1-101

Pflugmacher S, Jung K, Lundvall L, Neumann S, Peuthert A (2006) Effects of cyanobacterial toxins and cyanobacterial cell-free crude extract on germination of Alfalfa (Medicago sativa) and induction of oxidative stress. Environ Toxicol Chem 25:2381-2387. https:// doi.org/10.1897/05-615r.1

Pflugmacher S, Aulhorn M, Grimm B (2007a) Influence of a cyanobacterial crude extract containing microcystin-LR on the physiology and antioxidative defence systems of different spinach variants. New Phytol 175:482-489. https://doi.org/10.111 1/j.1469-8137.2007.02144.x

Pflugmacher S, Hofmann J, Hübner B (2007b) Effects on growth and physiological parameters in wheat (Triticum aestivum L.) grown in soil and irrigated with cyanobacterial toxin contaminated water. Environ Toxicol Chem 26:2710-2716. https://doi. org/10.1897/07-145.1

Preece EP, Hardy FJ, Moore BC, Bryan M (2017) A review of microcystin detections in estuarine and marine waters: Environmental implications and human health risk. Harmful Algae 61:31-45. https://doi.org/10.1016/j.hal.2016.11.006

Preußel K, Chorus I, Fastner J (2014) Nitrogen limitation promotes accumulation and suppresses release of cylindrospermopsins in cells of Aphanizomenon sp. Toxins (Basel) 6(10):2932-2947. https://doi.org/10.3390/toxins6102932

Scholz SN, Esterhuizen-Londt M, Pflugmacher S (2017) Rise of toxic cyanobacterial blooms in temperate freshwater lakes: causes, correlations and possible countermeasures. Toxicol Environ Chem 99:543-577. https://doi.org/10.1080/02772248.2016.1269332

Spoof L, Catherine A (2017) Appendix 3: table of microcystins and nodularins. In: Meriluoto J, Spoof L, Codd GA (eds) Handbook of cyanobacterial monitoring and cyanotoxin analysis. Wiley, Chichester, pp 527-537

Tsuji K, Masui H, Uemura H, Mori Y, Harada K (2001) Analysis of microcystins in sediments using MMPB method. Toxicon 39:687692. https://doi.org/10.1016/S0041-0101(00)00196-3 